\title{
Effect of flask closure method on occlusal vertical dimension of complete upper and lower dentures
}

SADJ October 2021, Vol. 76 No. 9 p517 - p523

LG Maguga', SR Mthethwa²

\begin{abstract}
Introduction

The movement of teeth during processing of complete dentures disturbs the harmonious occlusal scheme established at the final wax try-in stage.
\end{abstract}

Aims and objectives

To investigate the effect of RS flask closure on occlusal vertical dimensions of complete dentures. The mean occlusal vertical dimension of complete maxillary and mandibular dentures fabricated by the conventional flask closure were measured and compared with that of dentures fabricated by RS flask closure.

\section{Design}

A pretest-posttest control group experimental design.

\section{Methods}

Thirty sets of complete maxillary and mandibular wax trial dentures were randomly assigned to experimental groups. Fifteen sets were assigned to conventional flask closure and the remainder to RS flask closure. Compression molding with a long curing cycle was performed for the processing of the dentures. Pre-processing and postprocessing occlusal vertical dimensions were determined.

\section{Results}

The mean occlusal vertical dimensions of wax trial dentures assigned to either group were similar. The data produced substantial evidence to reject the null hypothesis that the post-processing mean occlusal vertical dimensions of both groups were equal.

Author affiliations:

1. Lesibana Godfrey Maguga: ND (Dental Technology), BTech (Dental Technology). Tshwane University of Technology. ORCID Number: 0000-0003-1284-3147.

2. Sibusiso Rockfort Mthethwa: $B D S, M P H, P h D$. Sefako Makgatho Health Sciences University. ORCID Number: 0000-0003-0420-808X

Corresponding author:

Dr SR Mthethwa: Medunsa Campus, PO Box D24, Sefako Makgatho Health Sciences University 0204

Tel: 0125215888 / Fax: 0125124274

Email: rocky.mthethwa@smu.ac.za

\section{Author contributions:}

1. Lesibana G Maguga: conception; design; acquisition of data; revising the article critically for important intellectual content

2. Sibusiso R Mthethwa: - analysis and interpretation of data; drafting the article

\section{Conclusion}

The occlusal vertical dimensions produced by dentures clamped by the RS flask closure were significantly less than those produced by dentures clamped by the conventional flask closure.

\section{INTRODUCTION AND BACKGROUND}

Tooth movement during the laboratory processing of complete dentures is well researched. A recent systematic review combined information from 114 published studies found in PubMed on the factors and variables involved in complete denture processing that can contribute to tooth displacement and the precautions required to minimize it. The review concluded that there are two main factors responsible for occlusal discrepancies in the processed dentures: change in the relationship of a tooth / teeth to the master cast during processing as a result of investing procedure, careless packing of acrylic resins in the mould cavity, or improper flask closure and warpage of the denture base due to release of inherent strains when the denture is separated from the cast. ${ }^{1}$

Vertical tooth movements which occur during denture processing may alter the occlusal vertical dimension, which the Glossary of Prosthodontic Terms (2017) defined as the distance between two selected anatomic or marked points (usually one on the tip of the nose and the other on the chin) when in maximal intercuspal position. ${ }^{2}$ Clinical studies have shown increased (excessive) occlusal vertical dimension (OVD) to be a common fault of many dentures. ${ }^{3}$ The direct consequence of an increased OVD is a reduction of the freeway space, which is defined as the distance between the occluding surfaces of the maxillary and mandibular teeth when the mandible is in a specified position. ${ }^{2}$ Freeway space is also referred to as interocclusal rest distance or space. ${ }^{2}$ The incorrect measurement of OVD and resultant provision of insufficient freeway space has been found to lead to teeth clashing; difficulties approximating the lips; discomfort brought about constant stimulation of the muscles; poor appearance; cheek biting; angular chelitis; temporomandibular joint pain; Costen's syndrome and masticatory inefficiency. ${ }^{4}$

To recover the proper vertical dimension of occlusion, a time-consuming occlusal adjustment is necessary that often destroys the anatomy of the artificial teeth. ${ }^{5}$ Various studies have been conducted to identify improved materials and processing techniques to minimize changes 
in the occlusion. ${ }^{6}$ The effect of flask closure method has been studied. Denture bases fabricated by the Rafael \& Saide (RS) flask closure method using the long curing cycle were found to be more dimensionally stable. ${ }^{7.8}$ The reduction in base inaccuracies allowed the teeth to preserve their position in the dentures. ${ }^{9,10}$

The RS flask closure method was proposed as an alternative to conventional flask closure method. In the conventional flask closure method, pressure is released when the flask is removed from the manual or hydraulic press and placed in the spring clamp. In contrast, in the RS flask closure method, the flask halves remain in contact when the flask is removed from the hydraulic press thus maintaining the acrylic resin under constant pressure conditions. ${ }^{7}$

The effect of the RS flask closure on linear displacement of maxillary denture teeth is not well defined. Conflicting results have been reported. Whereas, the results of a study by Negreiros, Consani, Mesquita, Sinhoreti and Faria (2009) ${ }^{11}$ found that in the immediate post-pressing time, the tooth movement was significantly greater for the conventional flask closure method and no statistically significant difference was observed between the post-pressing times in all distances evaluated in dentures obtained by the RS flask closure method, Consani, Domitti, Mesquita and Consani (2006) ${ }^{12}$ and Negreiros, Consani and Mesquita (2008) ${ }^{13}$ reported that tooth movement was similar in dentures processed by traditional closure and by RS flask closure. All three studies examined the displacement of maxillary denture teeth.

\section{Aims}

To test the hypothesis that the occlusal vertical dimensions produced in complete maxillary and mandibular dentures clamped by the RS flask closure method were significantly less than those produced by dentures clamped by the conventional method.

\section{OBJECTIVE OF THE STUDY}

To measure and compare the mean occlusal vertical dimension of complete maxillary and mandibular dentures fabricated by the conventional method with that of dentures fabricated by the RS flask closure technique using the long curing cycles.

\section{MATERIALS AND METHODS \\ Design}

This was a pretest-posttest control group experimental design.

\section{Target population}

The study population consisted of thirty sets of simulated removable complete maxillary and mandibular dentures.

\section{Sample size}

Twenty-eight sets of simulated complete maxillary and mandibular dentures were eligible to participate in the study. Two sets of dentures were excluded from the study due to distortion in processing resulting from contraction and gaseous porosity.

\section{Allocation method}

A sequence of random numbers was generated by a statistician using the computer software program SPSS (IBM, 2018). ${ }^{14}$ The allocation sequence was concealed in a desktop computer until interventions were assigned by the supervisor (second author). The random allocation rule was implemented i.e. a subset of the total sample size was randomly assigned by the research supervisor to group $A$ (conventional flask closure method) and the remainder were assigned to group B (RS flask closure method).

\section{Blinding}

The researcher fabricated wax trial dentures, which were assigned sequential numbers from 1 to 30 . Fifteen sets of wax trial dentures were randomly assigned by the research supervisor to group A (conventional flask closure method) and the remainder were assigned to group B (RS flask closure method). The researcher (first author) was blinded to group assignment. Pre-processing and post-processing occlusal vertical dimensions were determined by the researcher in the presence of the supervisor. The dentures were processed according to group assignment.

\section{Interventions}

The standard methods of fabricating dentures described by Sowter $(1986)^{15}$ and Johnson, Patrick, Strokes, Wildgoose and Wood $(2016)^{16}$ were used to fabricate thirty sets of complete maxillary and mandibular wax trial dentures on type 3 dental stone casts of a prefabricated silicone mould on one semi-adjustable articulator locked only to allow a hinge movement and maintained the same vertical dimension. The prefabricated silicone mould is routinely used to prepare maxillary and mandibular stone casts for students. The wax trial dentures were randomly assigned to experimental groups and invested in flasks following the method described by Mosharraf, Iranmanesh and Sadeghi (2007). ${ }^{17} \mathrm{~A}$ single operator i.e. the researcher, carried out all the laboratory steps and procedures using a single articulator for all the set ups. The laboratory steps and procedures followed in fabricating complete dentures allocated to RS flask closure and the conventional flask closure were identical. The only difference in processing between the finished complete acrylic dentures were the methods used to close the flasks.

In the conventional flask closure, the acrylic resin dough was placed into the large half of the flask where the teeth were and pressed down firmly into the mould. The two halves of the flasks were closed in a hydraulic press until

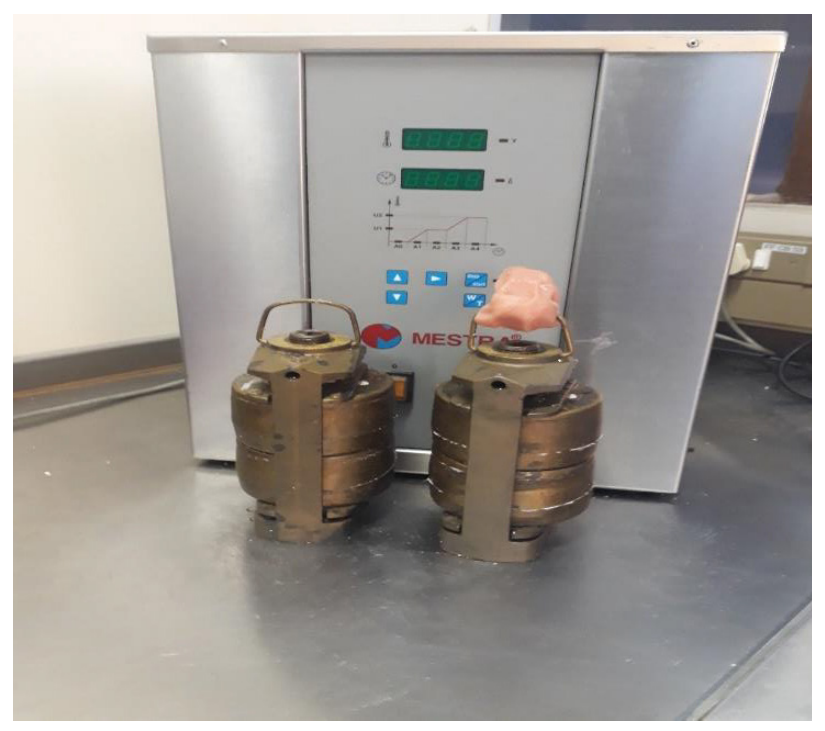

Figure 1: Conventional flask closure method 


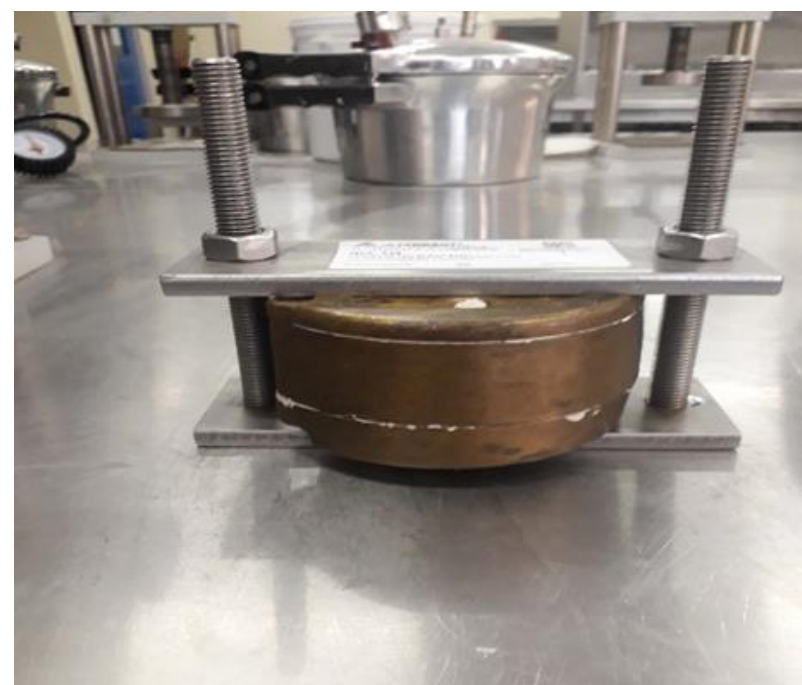

Figure 2: RS flask closure method the flasks were closed. Flasks were removed from the hydraulic press and transferred to traditional spring clamps.

In the RS flask closure, the acrylic resin dough was placed into the large half of the flask where the teeth were and pressed down firmly into the mould. The two halves of the flasks were closed and positioned between the 2 plates of the RS closure system and placed under pressure using a hydraulic press. The screws of the lower plate were fitted into the holes of the upper plate. After hydraulic flask pressure, the screw nuts were strongly tightened to the screws before press releasing.

Following flask closure, all denture sets were cured in a water bath. The temperature of the water curing bath was set to rise from $24^{\circ} \mathrm{C}-74^{\circ} \mathrm{C}$ in an hour and then maintain the temperature for 8 hours (long curing cycle). The processed dentures were allowed to cool down inside their curing water.

Figure 3: below is a flow diagram of the progress through the phases of the study (that is, enrolment, treatment allocation, follow-up, and data analysis).
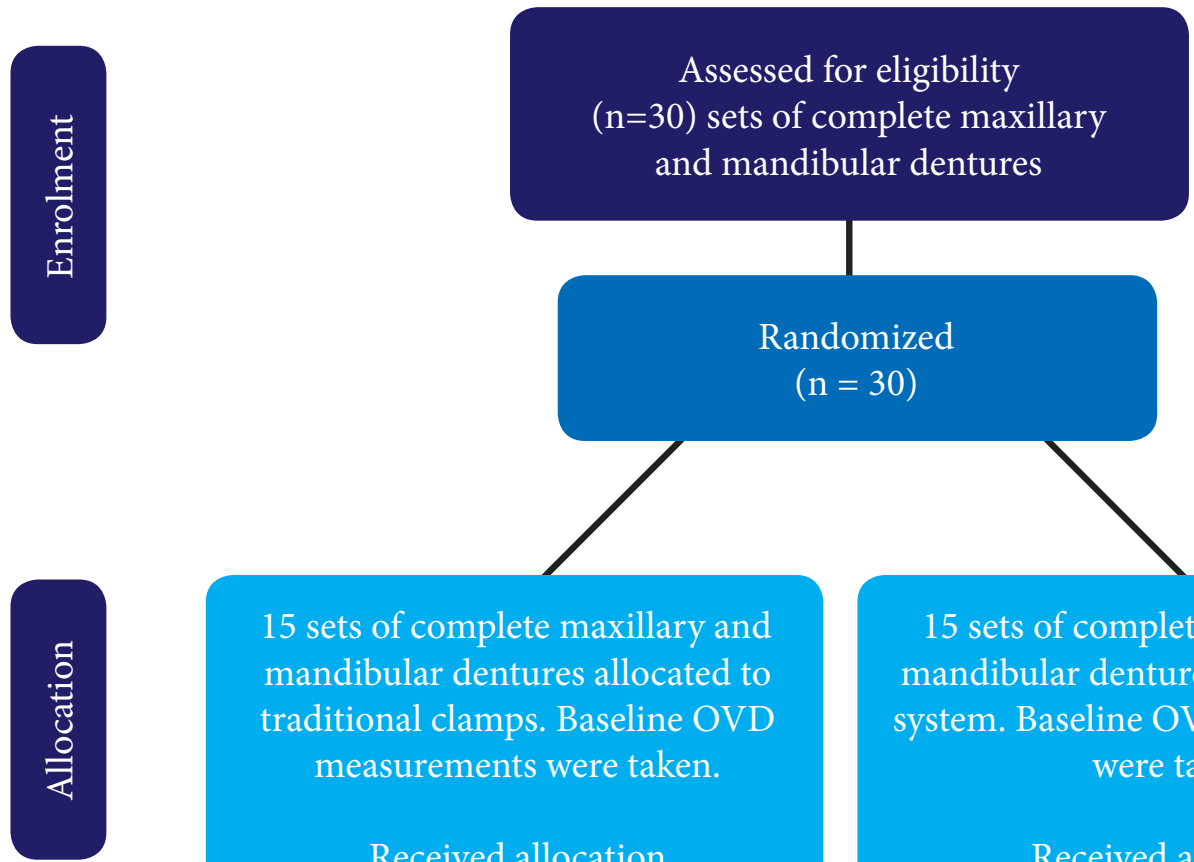

15 sets of complete maxillary and mandibular dentures allocated to traditional clamps. Baseline OVD measurements were taken.

Received allocation intervention $(n=14)$

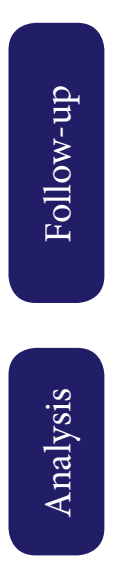<smiles>C1CCCCC1</smiles>

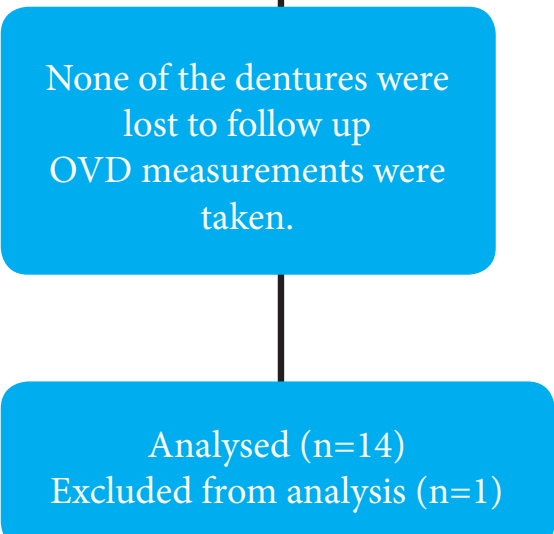

15 sets of complete maxillary and mandibular dentures allocated to RS system. Baseline OVD measurements were taken.

Received allocation intervention $(\mathrm{n}=14)$

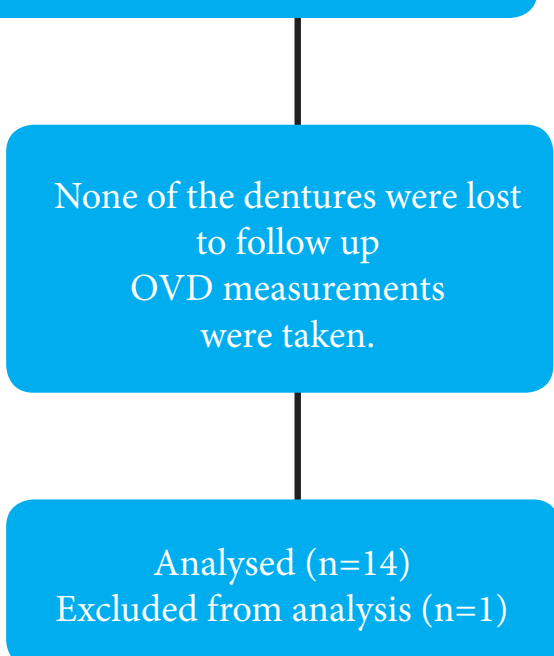




\begin{tabular}{|c|c|c|c|}
\hline Treatment & Sample size & Mean OVD (mm) & Standard Deviation \\
\hline Group A wax trial dentures & 14 & 134.548 & .03262 \\
\hline Group B wax trial dentures & 14 & 134.539 & .02731 \\
\hline Both groups & 28 & 134.544 & .02984 \\
\hline \multicolumn{4}{|c|}{$\mathrm{A}=$ conventional flask closure; $\mathrm{B}=\mathrm{RS}$ flask closure } \\
\hline \multicolumn{4}{|c|}{$\begin{array}{l}\text { The similarity in mean occlusal vertical dimensions indicate that the measurements were evenly distributed in the treatment groups. Th } \\
\text { mean occlusal vertical dimensions of both groups was } 134.544 \mathrm{~mm} \text {. }\end{array}$} \\
\hline
\end{tabular}

\begin{tabular}{|c|c|c|c|}
\hline \multirow[t]{2}{*}{ Groups } & \multicolumn{3}{|c|}{ Shapiro-Wilk } \\
\hline & Statistic & df & Sig. \\
\hline A & .931 & 14 & .313 \\
\hline B & .970 & 14 & .875 \\
\hline \multicolumn{4}{|c|}{$A=$ conventional flask closure; $B=R S$ flask closure } \\
\hline
\end{tabular}

Figure 4: Linear relationship between dependent and covariate by each level of the independent variable

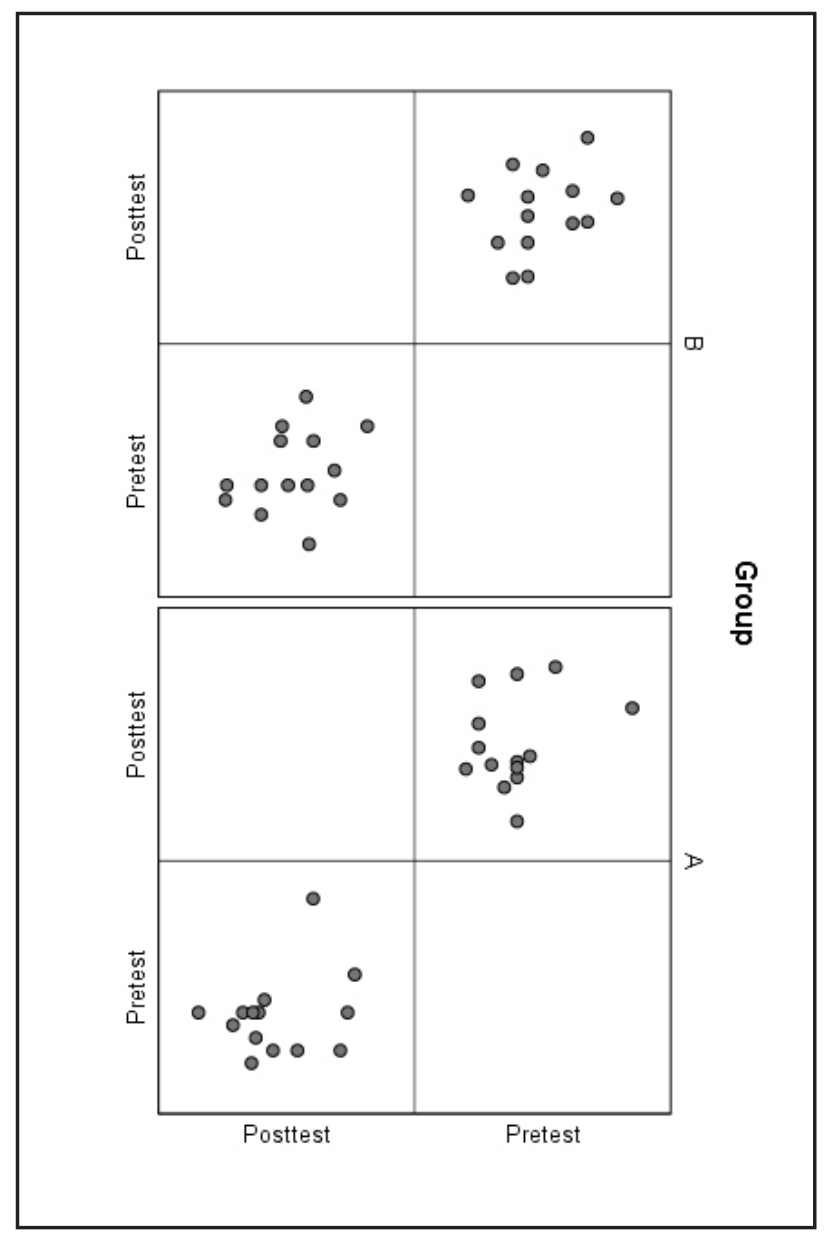

A = Conventional flask closure; $B$ = RS flask closure The left side of the scatter-plot matrix was interpreted. The points did not have an elliptical shape starting from the bottom left to the top right in the plot of pretest and posttest for group B (posttest is on $X$ axis and the pretest is on the $Y$ axis). The assumption of a linear relationship between dependent and covariate by each level of the independent variable was violated.

\section{Primary outcome}

The primary outcome was the mean occlusal vertical dimensions of each group. The occlusal vertical dimension was determined between reference lines marked on the maxillary and mandibular jaw members of the articulator, which was positioned on a table, using a digital Vernier caliper capable of registering changes as small as $0.01 \mathrm{~mm}$. The marks were maintained throughout 30 set ups and remounts. The effect of interest was the difference in mean OVD between pre-processing and post-processing measurements. The reliability of the OVD measurements was assessed by performing repeat measurements for a random sample $20 \%$ of the wax trial and acrylic dentures.

\section{Ethical considerations}

The study protocol was approved and permission to conduct the study was granted by the Faculty of Science Committee for Postgraduate Studies of the Tshwane University of Technology.

\section{STATISTICAL ANALYSIS/HYPOTHESIS TESTING}

Collected data were subjected to univariate analysis in Statistical Package for the Social Sciences (SPSS) software. Measures of central tendency and dispersion were calculated. ANCOVA was performed to evaluate whether the means of

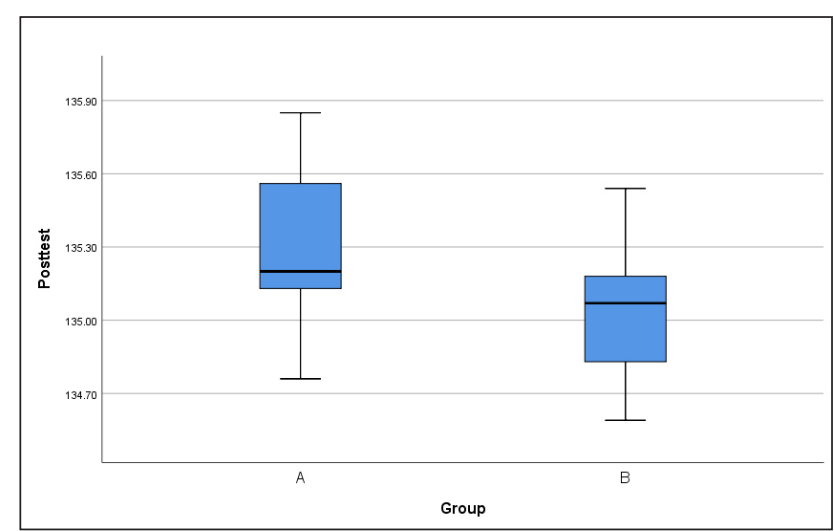

Figure 5: Outliers 


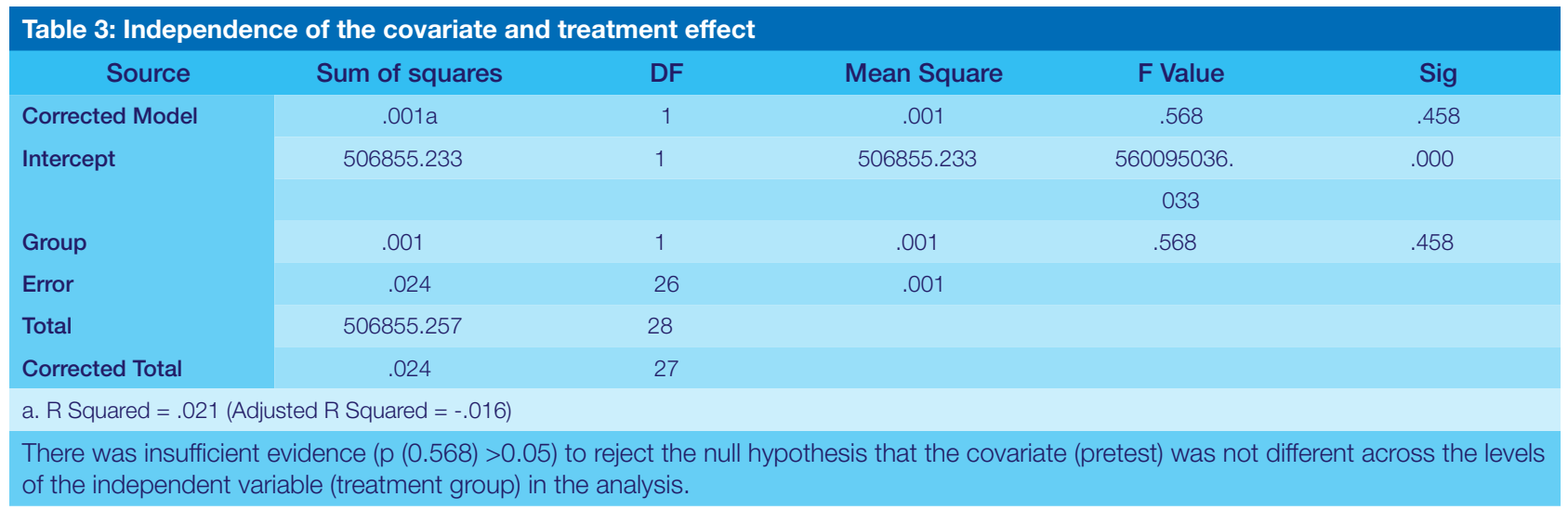

\begin{tabular}{|c|c|c|c|c|c|c|}
\hline Source & Sum of squares & DF & Mean Square & F Value & Sig & Partial Eta Squared \\
\hline Corrected & $.666 a$ & 3 & .222 & 2.440 & .089 & .234 \\
\hline \multicolumn{7}{|l|}{ Model } \\
\hline Intercept & .065 & 1 & .065 & .709 & .408 & .029 \\
\hline Group * & .001 & 1 & .001 & .009 & .927 & .000 \\
\hline \multicolumn{7}{|l|}{ Pretest } \\
\hline Group & .001 & 1 & .001 & .009 & .927 & .000 \\
\hline Pretest & .165 & 1 & .165 & 1.809 & .191 & .070 \\
\hline Error & 2.184 & 24 & .091 & & & \\
\hline Total & 511642.928 & 28 & & & & \\
\hline Corrected & 2.850 & 27 & & & & \\
\hline \multicolumn{7}{|l|}{ Total } \\
\hline \multicolumn{7}{|c|}{ a. $\mathrm{R}$ Squared $=.234$ (Adjusted R Squared $=.138$ ) } \\
\hline
\end{tabular}

the dependent variable i.e. post-processing mean occlusal vertical dimension were equal across levels of a categorical independent variable i.e. the group (conventional flask closure method = control, RS flask closure method = test), while statistically controlling for the effects of the covariate i.e. pre-processing mean occlusal vertical dimension. The level of significance was set at 0.05. Regression diagnostics was performed to evaluate the appropriateness of ANCOVA model. Six assumptions were checked to make sure that the covariate meets the requirements to run the ANCOVA. These were:

1. The dependent variable is normally distributed by each level of the independent variable

2. Outliers

3. Independence of the covariate and treatment effect

4. Linear relationship between dependent and covariate by each level of the independent variable

5. Homogeneity of regression slopes

6. Homogeneity of variance

\section{RESULTS}

Occlusal vertical dimensions (OVDs) of twenty-eight sets of complete maxillary and mandibular simulated dentures were analyzed. Figure 1 is a flow diagram of the progress through the phases of the study (that is, enrolment, treatment allocation, follow-up, and data analysis).

\begin{tabular}{|c|c|c|c|}
\hline F Value & DF1 & DF2 & Sig \\
\hline .243 & 1 & 26 & .626 \\
\hline \multicolumn{4}{|c|}{$\begin{array}{l}\text { There was insufficient evidence }(\mathrm{p}(0.626)>0.05) \text { to reject the } \\
\text { null hypothesis that the dependent variable variance was equal } \\
\text { across groups. The assumption of homogeneity of variance was } \\
\text { met. }\end{array}$} \\
\hline
\end{tabular}

\section{DISCUSSION}

This study was designed to determine the effect of RS flask closure method on the occlusal vertical dimensions of simulated dentures. The results indicate that the mean occlusal vertical dimension of trial wax dentures was 134.544 $\mathrm{mm}$. (Table 1). Differences in summary measures used to analyze results together with differences in the reporting of results made it difficult to compare the results of the current study with that of previous studies. The current study used occlusal vertical dimension measurements obtained between reference lines on the maxillary and mandibular jaw members of the articulator, which was positioned on a table whereas a number of previous studies used the average incisal pin opening to analyze their results. ${ }^{17-19}$ Several studies which obtained measurements in a comparable manner reported difference measures between preprocessing and post-processing measurements instead of the actual measurements. ${ }^{20-22}$ 


\begin{tabular}{|c|c|c|c|c|c|c|}
\hline Source & $\begin{array}{l}\text { Type III Sum of } \\
\text { squares }\end{array}$ & DF & Mean Square & F Value & Sig & Partial Eta Squared \\
\hline Corrected Model & $.665 a$ & 2 & .333 & 3.807 & .036 & .233 \\
\hline Intercept & .064 & 1 & .064 & .733 & .400 & .028 \\
\hline Pretest & .166 & 1 & .166 & 1.897 & .181 & .071 \\
\hline Group & .409 & 1 & .409 & 4.682 & .040 & .158 \\
\hline Error & 2.184 & 25 & .087 & & & \\
\hline Total & 511642.928 & 28 & & & & \\
\hline Corrected Total & 2.850 & 27 & & & & \\
\hline \multicolumn{7}{|c|}{ a. R Squared $=.233$ (Adjusted R Squared $=.172)$} \\
\hline
\end{tabular}

There was a statistically significant difference $(p(0.04)<0.05)$ in the dependent variable mean OVD across levels of the group when controlling for the covariate (pretest).

\begin{tabular}{|c|c|c|c|c|}
\hline Groups & Mean & Std. Error & Lower Bound & Upper Bound \\
\hline A & 135.299a & .079 & 135.136 & 135.463 \\
\hline B & $135.055 a$ & .079 & 134.891 & 135.219 \\
\hline
\end{tabular}

Table 8: Independent-samples t-test comparison of posttest descriptive means

\begin{tabular}{|c|c|c|c|c|c|c|c|c|}
\hline \multirow[b]{2}{*}{ Groups } & \multirow[b]{2}{*}{ Mean } & \multirow[b]{2}{*}{ Std. } & \multirow[b]{2}{*}{$\mathrm{t}$} & \multirow[b]{2}{*}{ Deviation } & \multirow[b]{2}{*}{ df } & \multirow[b]{2}{*}{ Sig. (2-tailed) } & \multicolumn{2}{|c|}{ 95.0\% Confidence } \\
\hline & & & & & & & $\begin{array}{c}\text { Mean } \\
\text { Difference }\end{array}$ & $\begin{array}{l}\text { Intervals for } \\
\text { Difference }\end{array}$ \\
\hline & & & & & & & Lower Limit & Upper Limit \\
\hline A & 135.3107 & .325 & 2.350 & 26.000 & .027 & .267 & .044 & . 490 \\
\hline B & 135.043 & .274 & & & & & & \\
\hline
\end{tabular}

The results of this study showed an even distribution of occlusal vertical dimensions at baseline between the groups (Table 1). These findings suggest that the randomization procedure achieved the goal of minimizing allocation bias. The results of the regression diagnostics showed that the data satisfied five of six underlying assumptions inherent in the ANCOVA model (Tables 2, 3, 4, and 5 and Figure 2). They confirmed that the ANCOVA model was the appropriate analysis for this study - consequently, the validity of the conclusions drawn could be relied upon.

This experiment found substantial evidence $(p(0.04)<0.05)$ to reject the null hypothesis that the posttest occlusal vertical dimensions were equal across levels of the group when controlling for the covariate (pretest) i.e. the difference in occlusal vertical dimensions between simulated dentures which were fabricated using RS flask closure method and those which were fabricated using the conventional flask closure method was statistically significant (Tables 6 and 8). This result has not previously been described. However, the findings of the current study support those of Negreiros and colleagues who found that in the immediate post-pressing time, the tooth movement was significantly greater for the conventional flask closure method compared with the RS flask closure method. ${ }^{11}$ More research needs to be undertaken before the relationship between occlusal vertical dimension and the RS flask closure method is more clearly understood.

The most interesting finding was that the lower limit of the 95\% confidence interval for the mean difference between simulated dentures fabricated using the RS flask closure method and those which were fabricated using the conventional flask closure method was very close to zero (Table 8). This indicates that the true difference may be very small and clinically meaningless despite the statistically significant result $(\mathrm{p}(0.027)<0.05)$.

Another important finding was that the 95\% confidence interval for the mean difference between simulated dentures fabricated using the RS flask closure method and those which were fabricated using the conventional flask closure method was wide (Table 8). A wide confidence interval however indicates that the estimate of the mean difference was not precise. A wide confidence interval results from a small sample and /or data with substantial variability, and is a suggestion of low power. ${ }^{23}$

\section{Limitations of the study}

A potential threat to the internal validity of this study was the large number of tests of statistical significance which were carried out. This increases the type 1 error rate, which leads to risk for spurious relationships and thus the conclusions that can be reached.

The small sample size gave rise to the wide confidence interval of the effect of interest

\section{CONCLUSION}

The mean occlusal vertical dimensions produced by dentures clamped by RS flask closure was significantly less than that produced by dentures clamped by the conventional flask closure. 


\section{References}

1. Ladha K, Tiwari B. Processing-induced tooth displacement and occlusal changes in complete dentures - an overview. Periodontics and Prosthodontics 2015;1(1:5): 1-8.

2. Glossary of Prosthodontic Terms, N. E., GPTष9. The Academy of Prosthodontics Foundation. J Prosthet Dent 2017;117(5S): e1-e105.

3. Abduo J, Lyons K. Clinical considerations for increasing occlusal vertical dimension: a review. Aust Dent J 2012; 57(1):2-10.

4. Chander NG, Venkat R. An appraisal on increasing the occlusal vertical dimension in full occlusal rehabilitation and its outcome. J Indian Prosthodont Soc. 2011;11(2):77-81.

5. Nogueira SS, Ogle RE, Davis EL. Comparison of accuracy between compression-and injection-molded complete dentures. J Prosthet Dent 1999; 82(3): 291300.

6. Basso MFM, Nogueira SS, Arioli-Filho JN. Comparison of the occlusal vertical dimension after processing complete dentures made with lingualized balanced occlusion and conventional balanced occlusion. J Prosthet. Dent 2006; 96(3): 200-4.

7. Consani RL, Domitti SS, Consani S. Effect of a new tension system, used in acrylic resin flasking, on the dimensional stability of denture bases. J Prosthet Dent 2002;88(3):285-9.

8. Consani RL, Domitti SS, Mesquita MF, Consani, S. Influence of flask closure and flask cooling methods on tooth movement in maxillary dentures. Journal of Prosthodontics 2006;15(4), 229-34.

9. Kyes FM (1951) Laboratory's role in successful full dentures. J Prosthet Dent 1951; 1(1-2):196-203

10. Wesley RC, Henderson D, Frazier QZ et al. Processing changes in complete dentures: Posterior tooth contacts and pin opening. J Prosthet Dent 1973; 29 (1): 46-54.

11. Negreiros WA, Consani RL, Mesquita MF, Sinhoreti MA, Faria, IR. Effect of flask closure method and postpressing time on the displacement of maxillary denture teeth. Open Dent J 2009; 3:21-5

12. Consani RL, Domitti SS, Mesquita MF, Consani S. Influence of flask closure and flask cooling methods on tooth movement in maxillary dentures. Prosthodont 2006;15(4):229-34.

13. Negreiros WA, Consani RL, Mesquita MF. Effect of the flask closure method contention method on the displacement of maxillary denture teeth. Brazilian Journal Oral Sciences 2008;7(24):1493-6

14. 'IBM SPSS Statistics for Windows, version XX (IBM Corp., Armonk, N.Y., USA)'6.

15. Sowter JB. Removable prosthodontic techniques. Dental Laboratory Technology Manuals, revised ed. USA: The University of North Carolina Press, 1986:25, 58-98.

16. Johnson T, Patrick DG, Stokes CW, Wildgoose DG, Wood DJ. Basics of dental technology: a step by step approach, 2nd ed. Wiley-Blackwell, 2016:42-51.

17. Mosharraf R, Iranmanesh F, Sadeghi E. A comparative study of changes in vertical dimension of occlusion using four different investing methods. The International Journal of Dental Science 2007;6(1):1-6

18. Barbosa DB, Compagnoni M A, Leles CR. Changes in occlusal vertical dimension in microwave processing of complete dentures. Brazilian dental journal 2002;13(3), 197-200.
19. Chintalacheruvu VK, Balraj RU, Putchala LS, Pachalla $S$. Evaluation of three different processing techniques in the fabrication of complete dentures. J Int Soc Prev Community Dent 2017; 7(Suppl 1): S18-S23.

20. Alaa'a MS. Influence of high expansion dental stone used as investing medium on the changes in occlusal vertical dimension of complete dentures. The Saudi Dental Journal 2013;25(4):135-40.

21. Lima APB, Vitti RP, Amaral M, Neves ACC. Effect of polymerization method and fabrication method on occlusal vertical dimension and occlusal contacts of complete-arch prosthesis. J Adv Prosthodont 2018; 10(2): 122-7.

22. Hasan RMA. Attempts to Minimizing Incisal Pin Opening During Processing of Complete Dentures. Erbil Dental Journal 2018;1(2), 78-85.

23. Petrie A, Sabin C. Errors in hypothesis testing. Medical statistics at a glance. 2nd ed. Massachusetts: Blackwell Publishing, 2005: 44-5 